Erkrankungsprozess ihrerseits, sei es durch irgend welchen ihrer Umgebung;

4. die Fälle von solitärer Genitultuberkulose an Kindern wie an Personen mit Atresie der Scheide, bei welchen eine direkte Infektion a priori ausgeschlossen ist.

\title{
Literatur.
}

1. Alterthum, Hegars Beiträge. Bd. I.

1a. Derselbe, Centralb]. f. Gyn. 1902. No. 8.

2. Emanucl, Zeitschr. f. Geb. u. Gyn. 13d. XXIX.

3. Fränkel, Jahrb. des Hamb. Staatskrankenhauses. 1893/94.

4. Frank, Monatsschr. f. Gob. u. Gyn. 13d. X.

5. v. Franqué, Zeitschr. f. Geb. und Gyn. Bd. XXXVII, 2.

6. Glockner, Hegars Beiträge. IBd. V, 3.

7. Kaujmann, Zeitschr. f. Geb. und Gyn. Bd. XXXVII, 1.

8. Michaelis, Hegars Beiträge. Bd. III, 1.

9. Nebesky, Monatsschr. f. Geb. und Gyn. I3d. XXII, 5.

10. Voigt, Arch. f. Gyn. Bd. LIX, 3.

11. Hartz, Monatschr. f. Geb. und Gyn. Bd. XVI. U'ber 'Tuberkulose der weibl. Genitalorgane. Sammelreferat.

12.A.Martin| Monatsschr. f. Geb. und Gyn. Bd. XVI, Ergünzungsheft. Veit, J Über Genitaltuberkulose. Ref.v.internat. Kiongress zu Rom 190를

13. Gottschalk, Arch. f. Gyn. Bd. LXX, 1.

14. Amann jr., Monatsschr. f. Geb. und Gyn. Bd. XVI, Ergänzungsh.

VII.

\section{Ùber die Aussichten der aktiven und passiven Immunisierung der Menschen gegen Streptokokken ${ }^{1}$.}

\author{
Von \\ Priv.-Doz. Dr. W. ZANGEMEISTER \\ in Königsberg i. I'r.
}

(Hierzu Tafel 11I.)

Es kann hier nicht meine Aufgabe sein, die Frage der Streptokokken-Immunität in erschöpfender Weise abzuhandeln. Ich muss mich hier vielmehr darauf beschränken, aus dem in Rede stehenden Gebiet diejenigen Fragen herauszugreifen, von deren Lösung die

1) Vortrag, gehalten am 15. VI. 1907 in der Ost- und Westpreuss. (ies. f. Gyn. zu Danzig. 
Möglichkeit, gegen Streptokokken zu immunisieren, im wesentlichen abhängt, und auch diese nur, soweit ich durch eigene Untersuchungen glaube zu ihrer Aufklärung beitragen zu können.

Die nicht spezifischen Schutzstoffe, welche die Widerstandskraft des Organismus gegen Streptokokken-Infektionen erhöhen sollen, treten im Tierexperiment so ausserordentlich rurück gegenüber den spezifischen ,Immunkörpern“", dass die letzteren in erster Linie unser Studium in Anspruch nehmen müssen.

Die Aussichten, gegen Streptokokken immunisieren zu können, sind wesentlich günstigere geworden durch den Nachweis der Arteinheit dieser Erreger. Denn die gleichzeitige Immunisierung eines Organismus gegen verschiedene Arten, die Herstellung ,polyvalenter“" Sera, stösst dadurch auf grosse Schwierigkeiten, dass niemals alle zur Immunisierung benutzten Komponenten in gleicher Weise die Produktion von Schutzstoffen auslösen und somit ein sicherer Schutz gegen die einzelnen Arten nie zu erreichen gewesen wäre.

Heute kann als feststehend gelten - und ich kann dies auch durch neverliche Untersuchungen wieder bestätigen -, dass man mit jedem Stamm gegen jeden anderen immunisieren kann, sofern nur der zur Immunisierung benutzte Stamm gewisse Eigenschaften besitzt, welche wir ihm aber anzüchten können.

Ich kann hier auf die zahlreichen, vielfach variierten und wiederholten Versuche im einzelnen nicht eingehen und muss mir dies für eine ausführliche Publikation vorbehalten.

Hier kann ich nur die Schlussfolgerungen aus meinen Versuchen kurz skizzieren.

Ich konnte durch frühere Untersuchungen (mit Dr. Meissl), sowie durch weiter fortgesetzte Versuche fesstellen, dass eine erste Vorbedingung für die Immunkörperproduktion die Pathogenität des Streptokokkenstummes für das zu immunisierende Tier ist.

Avivulente Stämme lösen, auch wenn sie für andere Tierarten hochvirulent sind und auch dann, wenn sie in grossen Mengen einverleibt werden, keine praktisch brauchbare Immunkörperbildung aus.

Früher nahm man an, dass menschenvirulente Streptokokken in der Regel auch tiervirulent seien; man trennte ganz allgemein virulente, pathogene Stämme von nicht pathogenen.

Ich konnte - ebenso wie wiederholt auch andere Autoren feststellen, dass Menschen- und Tierpathogenität grundverschieden sind. Gerade die von tödlichen Streptokokken-Erkrankungen vom Menschen gezüchteten Stämme erwiesen sich in der grossen Mehrzahl als avirulent für Mäuse und Kaninchen. 
Die gelegentlich gefundenen tiervirulenten Stämme aber fanden sich nicht bei infektiösen Fällen, sondern zumeist bei fieberlosen Wöchnerinnen $u$. dergl.. hatten also offenbar am Menschen saprophytisch vegetiert.

Stämme, welche für eine Tierart hochvirulent waren, erwiesen sich häufig auch in enormen Dosen völlig ungiftig für andere.

In dieser Richtung scheint mir die von mir festgestellte Tatsache wichtig zu sein, dass sich die Virulenz für eine Tierart durch Passagen durch eine andere Tierart herabsetzen lässt.

Das ist nur so zu erklären, dass die Angriffsorgane der Streptokokken, ihre Rezeptoren, für verschiedene Tierarten verschieden sind und durch Züchtung im Körper individualisiert werden.

Stellen wir uns einen Streptokokkenleib nach Ehrlich schematisch vor, so wird er lediglich diejenigen Rezeptoren besitzen, welche er infolge der Bedingungen, unter denen er bisher existierte, erworben hat. (Siehe die Tafel.)

Ein menschenvirulenter Stamm wird z. B. nur sehr wenig oder gar keine ,Mäuserezeptoren" haben. Durch eine Anzahl von Mäusepassagen werden die,,Menschenrezeptoren“" (blau) atrophieren und dafür „Mäuserezeptoren" (rot) neugebildet. Ebenso liegen die Verhältnisse bei verschiedenen Tierarten unter sich.

Während der qualitative Unterschied zwischen Menschen- und Mäuserezeptoren ein sehr grosser sein muss, wie aus meinen Untersuchungen hervorgeht, besteht z. B. zwischen Mäuse- und Kaninchenrezeptoren eine gewisse $\ddot{h}$ nlichkeit; denn es gelingt relativ leicht, mäusevirulente Stämme allmählich auch für Kaninchen hochvirulent zu machen und umgekehrt. Andererseits wirken abor selbst hochvirulente Mäuse- und Kaninchenstämme z. B. bei Tauben und Hühnern gar nicht.

Bei der bekannten ausserordentlich hohen Spezifität der Immunkörper müssen sich diese Differenzen im Rezeptorenbau des Streptococcus auch in der Konstitution des Immunkörpers (Ambozeptors) wiedergeben. Ein durch Mäuserezeptoren bedingter Irnmunkörper wird nicht gegen. Menschenrezeptoren wirken können u.s.f.

In der Tat konnte ich nachweisen, dass die im Organismus des Pferdes gebildeten Immunkörper - wie wir sie in starker Konzentration im Aronson-Serum haben - am Menschen unwirksam sind (obwohl sie z. B. beim Kaninchen und der Maus wirken). Andererseits waren die im menschlichen Organismus (nach Iberstehen schwerer Streptokokken-Infektionen) gebildeten Immunkörper stets unwirkeam an der Maus. 
Es geht daraus hervor - was zu erwarten war -, dass der durch Mäuserezeptoren ausgelöste Ambozeptor keine Affinität zu den Menschenrezeptoren der Streptokokken hat und umgekehrt. dass(schematisch)die cytophileGruppe des Mäuse-Ambozeptors nicht auf den Menschenrezeptor passt und umgekehrt (s. die Tafel III).

Entsprechend der von mir vorhin erwähnten Ähnlichkeit zwischen Mäuse- und Kaninchenrezeptoren zeigte sich auch eine entsprechende Ähnlichkeit in dem zugehörigen Ambozeptor. Denn es gelingt, Näuse durch Kaninchen-Immunserum zu schützen.

Als zweites Postulut für die Immunkörperbildung im Tierkörper ist die Lebenstätigkeit der Streptokokken zu nennen.

Die Einverleibung abgetöteter Streptokokken verleiht, selbst wenn sie in grossen Mengen und wiederholt geschieht, dem Tier nicht einmal soviel Schutz, dass dasselbe gegen eine die Dosis let. minima kaum übersteigende Infektion mit demselben Stamm, der zur Immunisierung benutzt wurde, geschützt ist.

Ich konnte auch die Ursache dieser Erscheinung aufklären: während andere Bakterienarten in ihrem Zellinneren Giftstoffe (Endotoxine) enthalten, welche vielfach eine enorm hohe Toxizität besitzen, bewirken auch die grössten Mengen in irgend einer Form abgetöteter virulenter Streptokokken keinerlei schwerere Vergiftungserscheinungen, selbst dann nicht, wenn man die Auflösung der Streptokokken im Tierkörper durch vorherige grosse Dosen eines wirksamen Immunserums beschleunigt.

Kaninchen magerten nach mehrfachen sehr grossen Dosen nicht ab. Mäuse verhielten sich völlig wie gesunde. Wenn die Existen\% jeglichen Endotoxins auch nicht geleugnet werden soll, so muss man die Giftigkeit abgetöteter Streptokokken doch als eine sehr geringe bezcichnen, wenn man \%. B. Mäusen ohne Schaden das Sediment von $1 / 4$ Liter Bouillonkultur einspritzen kann von einem Stamm, der sonst bis zu ${ }^{1}{ }_{1000}$ ccm tödlich ist! Die Art der Abtötung war für diescn Effekt gleichgültig.

Bekanntlich reagiert der Körper aber nur dann mit der Bildung von Immunkörpern, wenn das Zellprotoplasma genügend stimuliert wird.

Bei den Streptokokken liegt, wie weitere Untersuchungen gezeigt haben, die Schwelle für den hier nötigen Reiz des Protoplasmas relativ hoch: ich konnte nämlich (z. T. gemeinsam mit Herrn MeisslWien) feststellen, dass eine für praktische Zwecke genügende Immunität beim Tier nur dann erzielt wird, wenn dasselbe während der Immunisierung eine schwere Reaktion durchmacht; ein Teil der 
Tiere geht dabei stets zu Grunde, bevor der gewünschte Effekt erzielt ist.

Von grösster praktischer Bedeutung ist die Erfahrung, dass Tiere, welche sich noch nicht genügend von der Immunisierungserkrankung erholt haben, eine erhöhte Empjänglichkeit gegenüber Streptokokken-Infektionen haben und dass dieses Zeitintervall individuell sehr verschieden gross ist.

Jiese auch bei anderen Erregern gefundene Tatsache macht die Verwendung der aktiven Immunisierung am Menschen vorläufig unmöglich, ganz abgesehen davon, dass wir uns zur Injektion lebender, menschenvirulenter Streptokokken kaum werden entschliessen können, um eine vielleicht später drohende Streptokokkeninfektion zu vermeiden!

Es ist nicht ausgeschlossen, dass uns das Tierexperiment neue Tatsachen in die Hand gibt, welche uns gestatten, die Reaktion am Menschen genau zu bemessen. Vorderhand ist das nicht der Fall.

Aber selbst wenn dieses Problem gelöst würde, verspreche ich mir von der aktiven Immunisierung des Menschen für die Praxis nicht viel. Denn die Vorbehandlung wird auf jeden Fall, wie beim Tier, längere Zeit in Anspruch nchmen. Die meisten Eingriffe, auf die es hier ankommt (z. B. die Karzinome), gestatten aber ein vielwöchentliches Warten nicht.

Viel günstiger sind die Aussichten, die passive Immunisierung am Menschen zu verwenden. Mit ihr können wir Tiere ohne längere Vorbehandlung und auf völlig ungefährliche Weise mit Sicherheit gegen ein Vieltausendfaches der tödlichen Infektions-Dosis schützen.

Der enorme Wert eines Serums, welches ,passiven“ Schutz zu verleihen vermag, liegt ausserdem in der am Tier erwiesenen Möglichkeit, bereits ausgebrochene Infektionen zu heilen.

Leider fehlt uns vorläufig die Hauptsache: ein am Menschen wirksames Serum, wie ich bereits hervorgehoben habe.

Weder die Prüfung im Reagensglas, noch diejenige am Tier ist vorläufig für die Wirksamkeit eines Serums am Menschen. beweisend. Ja, man muss sogar hehaupten, dass ein an unseren Versuchstieren hochwirksames Serum aller Voraussicht nach am Menschen unwirksam sein wird. Denn das zur Immunisierung benutzte Tier muss auf die Einverleibung tiervirulenter Streptokokken stark reagiert haben. Selbst bei gleichzeitiger Behandlung mit menschenvirulenten Keimen wird die Reaktion auf die letzteren eine minimale sein, auch wenn das Tier sonst von menschen virulenten Streptokokken angegriffen würde; denn der Organismus ist durch die tiervirulenten Kokken, gegen welche er sich mit Immunkörper- 
produktion wehrt, in so hohem Grade in Anspruch genommen, dass er auf den noch hinzukommenden geringeren Reiz, den die menschenvirulenten auf ihn ausüben, nicht reagieren kann.

Es entspricht dies der allgemeinen Erfahrung, dass Tiere, welche anderuceitig erkrankt sind, sich einer zweiten Infektion weniger gut erwehren können, dass sie Schutzstoffe in geringerer Menge bilden als gesunde $u$. ähnl.

Die Herstellung eines gegen menschenvirulente Streptokokken wirksamen Serums ist nach meinen Darlegungen nur möglich mit Hilfe einer Tierart, für welche menschenvirulente Streptokokken stets ebenfalls virulent sind.

Keines der im Handel befindlichen Sera kommt diesem Erfordernis bisher nach, und deshalb ist ihre Wirksamkeit am Menschen rundweg zu verneinen.

Die Aussichten, eine in dieser Hinsicht brauchbare Tierart zu finden, sind deshalb nicht gering, weil uns das Tierexperiment zeigt, dass selbst weniger nahe verwandte Tierarten ein am Tier wirksames Scrum liefern können. So wirkt z. J3. das Pferdeimmunserum an der Maus, am Kaninchen u. s. w.

Die Notwendigkeit, eine dem Menschen nicht zu fernstehende Tierart zu nehmen, ergiht sich ferner noch daraus, dass zur Wirksamkeit des Antistreptokokkenserums noch ein drittes Agens nötig ist, ein Komplement.

Ich kann auf Versuche, die das Gegenteil beweisen sollten, hier nicht näher eingehen.

Ich sclbst konnte aber durch anderutitige Bindung des Komplementes im Blut, also durch Ausschaiten des gesamter Komplementes, die Resisten\% von Versuchstieren gegenüber Streptokokkenintektionen gan\% erbeblich herabsetzen, und Wechsberg hat das gleiche erreicht durch ein Antikomplementserum.

Jas menschliche Konılement kann aber nur dann mit dem Immunserum zusammen in Aktion treten, wenn seine haptophore Gruppe auf die komplementophile Gruppe des Ambozeptors passt.

Da wir nun wissen, dass das Komplement verschiedener Tierarten schr verschieden ist, so wird ein bei der Immunisicrung von Tieren gewonnener Immunkörper, Ambozeptor, wohl zu dem Komplement eben diescr Tierart, aber vielleicht nicht zu dem des Menschen passen (Tafel III).

Jedenfalls muss auch aus diesem Grunde zur Immunserumherstellung ein dem Menschen nahestchendes Tier gewählt werden.

Eine Möglichkeit der passiven Immunisicrung möchte ich nicht unerwähnt lassen, welche sich unter günstigen äusseren Umständen 
einmal realisieren lässt: Es ist die U'bertragung des Serum vou Rekonvaleszenten nach (schwerer) Streptokokkeninfektion. Wir haben hier die günstigsten Verhältnisse, nämlich ein beim Menschen selbst gebildetes Immunserum. Vorausgesetzt, dass das betreffende Individuum sich von der Erkrankung schon genügend erholt hat, ist an dem Vorhandensein von Immunkörpern im Blut an der Hand des Tierexperimentes nicht zu zweifeln. Meine Versuche in dieser Richtung sind noch spärlich und erlauben mir noch kein Urteil über den praktischen Wert dieses Weges.

\section{Sammelberichte.}

I.

\section{Über Narkose im Allgemeinen, über Inhalationsnarkose im Speziellen.}

Sammelreferat unter Berücksichtigung der Literatur der letzten Jahre nebst kritischen Bemerkungen.

Von

Dr. OTTO ROITH, Heidelberg.

(Schluss.)

Wichtige Resultate haben die experimentellen patholdenischen, und physiologischen Arbeiten der letzten Jahre zutage gefördert.

Meyer kam in seinen grundlegenden Arbeiten ïber die Theorie der Alkoholnarkose zu folgenden Sichliissen:

1. Alle chemischen, zunächst indifferenten Stoffe, die für Fott und fettähnliche Körper löslich sind, müssen auf lebendes Protoplasma, sofern sie darin sich verbreiten können, narkotisch wirken.

2. Die Wirkung wird an denjenigen Zellen am ersten und stärksten hervortreten müssen, in deren chemischem Bau jene fettïhnlichen Stoffe vorwalten und wohl besonders wesentliche Trüger der Zellfunktionen sind: in erster Linie also an den Nervenzellen.

3. Die verhältnismässige Wirkungsstärke solcher Narkotika muss abhängig sein von ihrer mechanischen Affinitit zu fettïhnlichen Sub). stanzen cinerseits, zu den übrigen kö̈rperbestandteilen, d. i. hauptsïchlich Wasser, andrerseits; mithin von dem T'eilungskoffizienten, der ihre Verteilung in einem (xemisch von Wasser und fettähnlichen Substanzen bestimmt. 